\title{
A Multimedia Approach to ODL for Agricultural Training in Cambodia
}

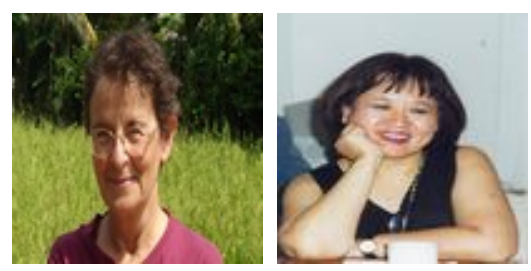

Helena Grunfeld

Victoria University, Australia

Maria Lee Hoon $\mathrm{Ng}$

International Development Research Centre (IDRC), Singapore

\section{Abstract}

Open distance learning (ODL) has long been an important option for formal and nonformal education (NFE) in most developed and developing countries, but less so in postconflict countries, including Cambodia. However, in Cambodia there is now greater awareness that ODL can complement traditional face-to-face educational approaches, particularly as there is a shortage of teachers in the country. Thus, understanding how ODL can achieve learning and other objectives has important implications for both formal education and NFE. If it can be found to be effective, ODL has the potential of reaching a large number of people at comparatively lower average costs. This paper reports on a project where the same content was taught to farmers in Cambodia via traditional face-to-face and via ODL and compares outcomes between the different training methods. Exploring the extent to which farmers had adopted new farm practices taught in the course, our results indicate that the outcomes did not vary considerably between those trained using the different approaches.

Keywords: Distance education; open learning; Cambodia; farming; multimedia; mobile learning 


\section{Introduction}

This paper summarises an evaluation of a pilot non-formal ODL project for farmer education in Cambodia, in which one face-to-face and two ODL approaches were compared for self-reported adoption of new agriculture practices by the participants on their farms. Since the 1960s, ODL has been an important option for formal and NFE in developed countries, sometimes providing a cheaper option for meeting the needs of learners who are not able or prefer not to attend regular face-to-face classes. The use of ODL has escalated with the availability of information and communication technologies (ICTs). J ung, et al. (2011) pointed to evidence of progress made in distance education in Asia with respect to access, equity, and cost-benefits, but Perraton (2004) cautioned that ODL does not always reduce unit costs of education. Understanding whether and how ODL can contribute to learning and change behaviour in on-farm practices is important for rural development. This is especially so where there is a shortage of qualified teachers, often the case in rural areas in the developing world. These areas also tend to have a large and growing proportion of youth, who might be more likely to migrate to urban areas in the absence of local learning opportunities. Teacher shortages are particularly felt in Cambodia, which is still recovering from thirty years of civil war, including the devastation of the Khmer Rouge rule. During this time, the skill base of the country was eroded and is only gradually being reconstructed. It was not until the establishment of the United Nations Transitional Authority in Cambodia in 1992 that the long path to normalisation commenced (UN, 2003).

Farmer training in developing nations has benefitted from the use of radio and video for many decades (Sulaiman, et al., 2012), but ODL based on multimedia accessed from computers is less common. ODL in developing countries faces different issues and problems from those encountered in the developed world (Wright, Dhanarajan, \& Reju, 2009). For example, there may be inadequate telecommunications infrastructure, ICT hardware and software, quality assurance, qualified staff to design and develop instructional material, and trained staff to support students. In addition, the learners may not have the skills needed to use self-study material effectively. This is a particular challenge, even in developed countries, for vocational training (Mikalsen, et al., 2008). Serious problems exist in relation to the building of instructional design capacity in Asia as there are relatively few well-trained instructional designers (Librero, 2010). However, ODL designed with proper student support systems has the potential of reaching a large number of people in a cost effective manner and inspiring learning. As noted by Gulati (2008), when addressing the above and other challenges of ODL in developing countries, it is also necessary to consider the distributional impacts of this mode of learning to ensure it does not only benefit those who are better off. This is particularly the case as it appears, from the literature on ODL in developing countries, that this form of learning is more prevalent in the higher education than in other sectors.

After describing the project and course participants, we discuss methodological options considered for assessing the effectiveness of the course and describe the research 
method of the evaluation. This is followed by a report on the outcomes of the evaluation and a discussion on possible implications.

\section{ODL in a Non-Formal Course on Farming Methods at Chea Sim University of Kamchaymear}

The project discussed in this paper involved the development, delivery, and assessment of a non-formal ODL course for farmers by the Chea Sim University of Kamchaymear (CSUK), a small rural university located approximately $120 \mathrm{~km}$ east of the Cambodian capital, Phnom Penh. The duration of the project, from training in the preparation of ODL course material until completion of course delivery, was 24 months. The project was managed by the Pan Asian Distance and Open Resources Access (PANdora) network and was supported by the International Development Research Centre (IDRC) of Canada. Its purpose was to test the efficacy of ODL compared to traditional face-toface learning.

Cambodia has had limited exposure to ODL. At the time of the course delivery and evaluation reported in this paper, there was no policy framework for ODL in the country. The outcome of this CSUK ODL course was one of the inputs into a policy dialogue ${ }^{1}$ with the Ministry of Education, Youth and Sport and IDRC in March 2012. This dialogue covered a range of issues associated with organising and structuring ODL, including governance structures, curriculum, content development and distribution, supporting and enabling environments, assessment, examination and certification, media and technologies, monitoring and evaluation for quality maintenance, and regulatory and legislative matters.

The project offered non-formal education and training for farmers in nine villages located in three communes in Kamchai Mear District, Prey Veng Province, in which 97\% of the villagers rely on subsistence farming as their primary livelihood (NCDD, 2009). The course was conducted from May 2011 - J an 2012, 12 weeks per learning mode. Three different training methods were used:

- traditional, face-to-face (FF) learning taught by CSUK lecturers;

- multimedia (MM) learning assisted by a facilitator, using self-instruction material on digital video discs (DVDs); and

- multimedia plus mobile phones (MP) for student learning support, using the same learning material as the MM group.

1 The policy conference was held on 27-29 March 2012, arranged by the Ministry of Education, Youth and Sport (MOEYS), with the technical and financial support of the International Development Research Centre of Canada. 
One important difference between the FF and the other two approaches from an ODL perspective was that the FF course was taught by a CSUK lecturer, while the other two courses were conducted by a non-expert facilitator.

The DVD multimedia courseware had been developed and designed by staff at the CSUK Faculty of Agriculture. It combines text, audio, and visual content, such as charts, pictures and videos, using the open source eXeLearning authoring application, and incorporates some interactivity. Each course participant in the MP group was provided with a mobile phone with camera, short messaging service (SMS), and multimedia messaging (MMS) capability. Although the devices were not smartphones, they had, unlike most standard mobile phones in Cambodia, localised Khmer script for SMS. Participants were shown how to use the phones, camera, SMS, and MMS. The cost of the phones and usage charges were covered by the project, so participants did not incur any expenses for these.

There is a large volume of literature dealing with the use of mobile phones for various agricultural applications (e.g., market information) (World Bank, 2011), but limited references to the use of mobiles for structured learning by farmers (COL, 2012). Mlearning, applied in several domains of learning, using different technologies, has attracted much scholarly attention (Ally, et al., 2009; Otieno, 2012; Rekkedal \& Dye, 2007), including its application in developing countries (Iqbal \& Qureshi, 2012; Isaacs \& Hollow, 2012). While there has been some research into the use of mobile devices for informal learning (Clough et al., 2009) and adult education (Aker, Ksoll \& Lybbert, 2011), its application as a supplement to non-formal courses in farming methods does not appear to have been the focus of much study.

The mobile phones were not used for what is traditionally considered m-learning (i.e., having learning material accessible on mobile phones) (Latchem, 2012). The purpose of the MP delivery was to enable participants to use phones in the field by sending SMS text or preferably MMS with pictures of plant or animal diseases to the lecturers to discuss what to do about these diseases, but there were not many interactions of this nature. Instead, participants tended to use the phones more to understand the learning content (e.g., they might contact the lecturer to ask for a definition of pollination, which was already in the learning material). This latter form of interaction could be perceived as forfeiting one of the benefits of ODL (a cost-effective strategy with low variable costs) as it expended much time of the lecturers (variable costs). However, there were positive aspects of this interaction in that participants used the mobile phones to ask questions in a culture normally characterised by rote learning and fear of asking questions (Berkvens, et al., 2012).

There were 90 course participants, 30 in each learning approach, studying in groups of 10. The same learning method was used in each group and there were thus three groups per learning method. The participants were randomly selected from the target villages, but not randomly assigned to groups. With a few exceptions, everyone in the same village participated in the same group. All participants had to be literate in Khmer. The 
training sessions for all three learning modes occurred in multi-purpose community telecentres (MCTs) near the participants' homes. An MCT consisted of a small room equipped with at least one computer and Internet access. These were installed as part of the IDRC-funded "Informatics for rural empowerment and community health (iREACH)" project. MCTs have been recognised as having potential to support ODL in the developing world (Latchem \& Walker, 2001; Mahmood, 2005). The session times had been established in consultation with participants to, as far as reasonably possible, accommodate their availability.

The course content was the same for the three learning modes, spanning a wide range of subjects, packaged into five modules consisting of 41 sub-topics with focus on practical implementation. The five modules were as follows: introduction to agriculture, rice farming, vegetable farming, forage crop farming, and animal husbandry.

Although the course also included some theoretical aspects, participants understood that the objective was to learn new farming techniques (e.g., how to build a chicken coop). In the MM and MP sessions, participants studied the course content on a DVD (no Internet access was required for this course) around one computer, assisted by a facilitator, who supported the trainees in using the computers and learning material and discussing how they could apply what they had learned. Most course participants lacked experience in handling computers and although some participants acquired basic computer skills, this did not form part of the course objectives. Informal feedback from the facilitator and some of the learners indicated that having only one computer was unsatisfactory and that two or three learners per computer would have been preferred, but neither additional space nor computers were available in the hubs.

There were also opportunities for course participants to share ideas in this learning environment. This instructional method is often referred to as blended learning, an approach that combines distance education delivery mediated by ICTs with supporting study groups and tutorials (Latchem, 2012). Such interaction among the learners, sometimes involving a facilitator and conducted with a high degree of informality, may overcome the challenge of learning practical skills via ODL. In order to learn practical skills, precise instructions must be given to enable learners to follow the processes taught in the material and repeat what is learned (Hampton, 2002). Also, participants may benefit if they can share their practical experiences with others (e.g., a video-based instructional vocational course for distance learners in Ghana, reported by Donkor, 2011, incorporated fortnightly tutorial sessions at a study centre).

\section{Characteristics of Course Participants}

All participants had attended at least primary school, 26\% primary, 36\% secondary, 25\% high school, and 13\% university, but not everyone had completed their respective level (e.g., one farmer had only two years of formal primary education). The average and mean years of schooling both centred around eight, with a range from 2-16 years. All of the 11 (four males and seven females) university-educated participants were in the MP 
group. Participation in the three learning types was evenly distributed between genders. The greatest discrepancy was that there were 17 females and 12 males in the MM group.

There were between 7-14 participants from each village. Except for one village, Kamchaymear Cheng, which had three male and eleven female participants, participation for all villages was relatively evenly spread gender-wise. The universityeducated participants resided in three villages only: five in Tropaign Skon, four in Snoul, and two in Kamchaymear Cheng. The least educated participants (none beyond secondary school) were concentrated in two villages, Lo Ark and Lor Eth. With a few exceptions, all participants from a village used the same learning method.

As shown in Table 1, women were somewhat overrepresented in the age group up to 40 years, with $80 \%$ in this group, compared to men, at $69 \%$. Different age groups were distributed across the three learning categories, but there was a bias toward younger farmers in the MP group, in which $75 \%$ were below 30 , but there was also a 61 year old man. A majority of participants (70\%) were married, but only $30 \%$ in the MP group, most likely due to the high proportion of young farmers.

Table 1

Age Profile of Participants

\begin{tabular}{|l|r|r|r|r|}
\hline Age group & Male & Female & Total & \% \\
\hline $18-20$ & 4 & 10 & 14 & $16 \%$ \\
\hline $21-30$ & 8 & 16 & 24 & $28 \%$ \\
\hline $31-40$ & 17 & 9 & 26 & $30 \%$ \\
\hline $41-50$ & 3 & 6 & 9 & $10 \%$ \\
\hline $51-60$ & 4 & 2 & 6 & $7 \%$ \\
\hline $61-68$ & 6 & 1 & 7 & $8 \%$ \\
\hline Total & 42 & 44 & 86 & $100 \%$ \\
\hline
\end{tabular}

From discussions with the course organisers it appears that mixing of age groups could have inhibited the learning process, but this did not appear to be the case with mixed gender groups. Interactions were sometimes reserved between people of different age groups, probably related to the deference shown to older people in traditional Khmer culture.

The main household income of the vast majority of respondents was derived from selling rice: more than $85 \%$ of participants in the FF and MP groups, but slightly less than half in the MP group, where there was a higher incidence of income from palm produce sale and other sources (not specified).

The farm size cultivated by course participants ranged from 0.24 to 9 hectares (ha), with the average and median sizes both approximately 2 ha. Although not evenly spread across the learning approaches, there was no particular land size bias in any group. For 
example, the FF group included six farmers cultivating $0-1$ ha, one with 9 ha, and one with 6 ha. None of the university-educated participants had more than 3 ha, while one man, aged over 60 with only primary education, cultivated 6 ha. On average, $80 \%$ of all land under cultivation by respondents was devoted to rice.

Approximately half of the participants had access to irrigation. Of the remaining, 32 responded explicitly that they did not have access, but 11 did not respond to this question. There was no apparent relationship between the three learning groups, land size, and/ or access to irrigation. Three of the four largest land holders had access, but the farmer with 6 ha did not.

In terms of ICT, there were different combinations of mobile phone, computer, radio, and television access. Eighty-six percent had access to mobiles, with seven participants having these as their only ICT. Three women and four men had computers. This low level of access is important when considering the approaches to be deployed in ODL programmes.

\section{Consideration of Research and Evaluation Approaches in the Study}

There were formative assessments throughout the course, mainly in the form of attendance, three assignments, and two examinations (mid-term and final). Neither quality assurance, such as student perceptions of the course material, nor formal assessments of how the participants in the MP group used the mobile phones, were conducted. But as mentioned above, from discussions with lecturers, it emerged that the phones were not used as intended. Rather than using the SMS and MMS functions to contact lecturers for guidance on specific issues encountered in the field, the phones were used to call the lecturers for clarification on the course content.

The assessments reported in this paper can be classified as summative evaluations, usually undertaken at an advanced or final point in the lifecyle of a project to explore the extent to which its objectives were met (Hudson, 2006; Lockee, Moore, \& Burton, 2000). Evaluations often centre on predetermined indicators, but it is also important to shift the focus away from these to make room for unintended outcomes or impacts, particularly to understand whether and how certain interventions have impacted on people's lives (Sanderson \& Kindon, 2004; Sen, 2001). In this study, we focused on the farmers' own account of how the course encouraged them to apply new farming methods.

Rather than a body of rules, summative evaluation must be tailored to individual situations and crafted to fit the purpose (Guba \& Lincoln, 1981). In our case, the research question was given: Is ODL as effective as face-to-face training in enabling farmers to expand their knowledge about scientifically based agricultural techniques, as reflected in the adoption of new practices covered in the course material. 
In order to ascertain the success of a particular mode of delivery, different measures could be used (e.g., knowledge acquisition, the extent to which the course fulfilled the participants' expectations, whether new practices were adopted, and/or how the new practices affected yields). As mentioned above, tests based on course content were conducted throughout the project period in order to explore whether there were any differences in knowledge acquisition using the different learning approaches. As the purpose of the agricultural course was not only to teach practical skills, but also to encourage farmers to adopt new practices, adoption rates were also considered an important outcome. The adoption of new practices also indicates agency (i.e., the ability of farmers to have better control over their lives, providing them with new capabilities in the form of freedom to experiment with new techniques). If individuals value what they have learned, they will apply it (Tikly \& Barrett, 2011).

Knowledge is implicit in adoption; farmers can only adopt practices they know about. Also, they are likely to consider applying them if they are aware of what benefits to expect compared to previous practices (Rogers, 2003). Furthermore, adoption indicates some form of achievement, while knowledge reflects only the potential to achieve. However, knowledge may not always translate into change of practice even where the farmer desires to adopt an innovation, but is unable to do so due to lack of other resources required for the change.

The quantity and quality of yields are ultimately the most important indicators for farmers as to whether their farming practices are successful. However, for this study, it was not considered possible for the evaluation to be based on these, which are affected by external factors such as weather and soil quality that are beyond the control of farmers and would be difficult and time-consuming to measure. Further, if one focuses on yields, the measurements would need to be conducted over a longer period of time than was available for the completion of the study. For some practices, there could be a trade-off between quality and quantity, adding another layer of complexity to the comparison. For these reasons, any focus on yields would have to cover a longer timespan than is compatible with the expectations of funding agencies. These usually require feedback shortly after the conclusion of a training programme. Furthermore, studying changes in yields is more complex than generally allowed for in budgets available for evaluations.

Due to the limited scope of this study, it is important to note that the data and associated interpretations serve to illustrate tentative outcomes rather than provide conclusive evidence on the success of the different learning approaches in encouraging farmers to adopt new practices.

\section{Research Framework and Methodology to Assess Changes in New Practices Adoption}

Following deliberations outlined in the previous section, we decided to focus on changes in practices, searching for signs of whether and how these had changed as a result of the 
course. While it would have been desirable to inspect farms for evidence of change, this was not possible due to resource constraints. Instead, we relied on self-reporting of adopted changes.

The research was carried out in two stages: focus groups (FG) and a survey. The purpose of the first step, conducted in late J anuary 2012, shortly after the delivery of the final course module, was to get an indication of the most important new practices that were likely to be adopted. This type of qualitative research approach is appropriate when studying how' questions (Yin, 1994). There were three focus groups, each with 10 participants from the same learning approach and with gender balance in each group. The results from the FGs informed the design of the survey questionnaire, which centred on what the FG participants perceived as the most important practices. The course covered too many topics for all to be included in the survey, considering the limited time available for the analysis.

For the survey instrument, all course participants, except three who had migrated from the area, were interviewed in March 2012 by students studying formal degree courses at CSUK. The questionnaire dealt with adoption of new practices and the primary data set consisted of responses to these questions. Most questions were open-ended, which made it quite time-consuming to code and analyse the results, but this approach had the benefit of enabling farmers to express themselves in their own terms. After coding, the data were analysed, mainly through cross-tabulations in the Statistical Package for the Social Sciences (SPSS), to see what similarities and differences emerged across the three learning modes with respect to changing methods and adoption of new practices. While a common questionnaire was used, it is possible that some questions might have been interpreted in different ways by some respondents.

\section{Research Results}

In the FG discussions, participants highlighted the importance of new rice cultivation practices and also referred to crop diversification and new ways of approaching animal husbandry. Similar issues were raised among participants from the three learning groups.

All course participants reported that they had adopted new practices: adoption of a new activity such as composting and the refinement of an existing activity. The number of practices changed for any one activity usually ranged from one to four. For the sake of taking into account the total number of new practices adopted in the comparisons, we developed the concept of "aggregate change", which for an activity is the sum of the number of farmers times the number of new practices. So, a farmer adopting four new practices was given a weight of four, compared with a farmer who only adopted one new practice. A farmer who started a new activity, say composting, was given one weight only, even if adopting several of the composting methods. As an indication of the 
relative efficacy of ODL in diffusing new practices compared with traditional face-toface training, we turn to Table 2, which shows the aggregate changes in the three learning groups.

Table 2

Total Number of Changes Adopted by Farmers

\begin{tabular}{|l|c|c|c|}
\hline Aggregate number of new changes related to: & FF & MM & MP \\
\hline - water management of rice fields & 33 & 46 & 44 \\
\hline - rice field levelling by moving earth from high to low lying areas & 12 & 13 & 13 \\
\hline - rice planting & 67 & 70 & 63 \\
\hline - applying fertilisers to rice & 63 & 54 & 52 \\
\hline - rice harvesting & 57 & 71 & 70 \\
\hline - farmers starting home gardens & 3 & 5 & 9 \\
\hline - new crops (based on number of new crops) & 92 & 82 & 77 \\
\hline - starting to use fertilisers for crops other than rice & 2 & 3 & 3 \\
\hline - new practices in applying fertilisers for crops other than rice & 30 & 33 & 32 \\
\hline - starting composting & 15 & 13 & 11 \\
\hline - starting to use chemical inputs & 2 & 4 & 1 \\
\hline - practices in using chemical inputs & 26 & 53 & 47 \\
\hline - practices in raising chicken & 72 & 75 & 76 \\
\hline - practices in raising pigs & 36 & 40 & 35 \\
\hline - acquiring cattle after the course & 4 & 9 & 7 \\
\hline - practices in raising cattle by those with cattle before the course & 36 & 26 & 22 \\
\hline - practices in raising fish & 11 & 10 & 8 \\
\hline Total number of changes & 561 & 607 & 570 \\
\hline
\end{tabular}

While the adoption rate in the different groups was not uniform, the results indicate consistent commonalities in that for some practices one learning group might have had a higher adoption rate, whereas for other practices, learners in another group had a higher propensity to adopt methods from the course material. Although we are primarily interested in the aggregate change in this comparison, the rest of the section summarises results for individual activities.

There was a higher rate of adoption of new methods for applying fertilisers in rice fields in the FF than the other two groups. Ten farmers, most of them in the MP group, did not adopt any new practices for fertilising their rice fields. A total of 19 different methods were listed by respondents. The most commonly reported change was to alter the frequency and timing of applying fertilisers during the growing cycle. There was hardly any difference between the groups in the adoption rate of fertilisers for other crops. The number of course participants who reported using composting increased from 15 before the course to 54 after, with the largest proportional increase in the MP group, but this could be explained by the low incidence of composting in that group prior to the course. In addition to the higher incidence of composting following the course, $73 \%$ of those who had used composting before changed some of their practices to new methods they had learned. With a lower proportion of farmers in the FF group using chemical inputs before the course, it was not surprising to see a lower incidence of change in that group. 
However, the average number of changed practices per farmer who used chemical inputs prior to the course was also lower for the FF group, 1.6 compared with 2.4 and 2.1 for the MM and MP groups, respectively. The most commonly reported change was to start using masks, mentioned by $39 \%$ of farmers in the FF group, compared with $58 \%$ and $48 \%$ in the MM and MP groups, respectively.

Respondents reported a total of 14 different methods they had applied for land levelling on their rice fields, of which we analysed only the most frequently adopted, moving earth from high to low lying areas of the rice fields. Approximately the same number (12 in the FF and 13 in the other groups) from each learning approach adopted this method. In total, respondents listed 14 different new rice planting methods adopted, with a maximum of four changes per farmer. The greatest discrepancy in the number of new rice planting practices between the groups was $10 \%$, with most new methods adopted in the MM group. Prior to the course, there did not appear to be much interest or skill in water management of rice fields, as reflected in responses like "no interest in the amount of water", "not taking care of dikes or water management", "keep water in the field until harvest", "no rice field dikes for water levelling". After the course, 41 participants (18 male and 23 female) claimed they "diked very well". These were distributed evenly across the learning groups (FF:12, MM:15, MP:14). It did not seem that access to irrigation made any difference either and there were in fact more farmers with access to irrigation who did not improve their dikes, compared to those who did. The aggregate number of new water management practices adopted by the MM and MP groups exceeded the number in the FF group by approximately $36 \%$.

The course included several methods for harvesting rice, including harvesting when the colour has changed to yellow, when $80-85 \%$ of the crop is ripe and after rice fields have been drained for 1-2 weeks before the harvest. Farmers in the MM and MP groups adopted new rice harvesting methods to a greater extent than those in the FF group.

Almost $75 \%$ of respondents had started planting new crops after the course and the total number of new crops mentioned by different respondents amounted to 23, comprising annual vegetables such as eggplant as well as perennials, including mango and pepper trees and water convolvulus (water spinach). The number of new crops grown by a farmer ranged from one to eight and in the aggregate, farmers in the FF group adopted new crops to a larger extent than the other groups, $12 \%$ and 19\% more than the MM and MP groups, respectively. Some of the new crops were grown in home gardens, which slightly over $60 \%$ of respondents cultivated before the course. This increased to almost $83 \%$ after the course, with no major gender differences between the groups. The highest increase was in the MP group, but this could be explained by members of this group having had the lowest incidence of home gardens before the course, only 15. The number of home gardens increased by three in the FF and five in the MM groups. After the course, all participants in two villages had home gardens, and in four villages, there was only one participant without a home garden. 
All but four course participants (three males and one female) raised chicken before the course. Two participants in the FF group and one in the MP group started chicken raising after the course. Changes in chicken raising practices were reported in all course categories, with an almost normal distribution around the change of 2-3 new practices, and the aggregate change indicated only marginal differences between the groups. The proportion (approximately 50\%) of participants raising pigs prior to the course was similar in the different learning approaches and every village had a mix of those who raised and did not raise pigs. Only three participants acquired pigs after the course, one in the FF and two in the MP groups. They used similar practices as those adopted by farmers who had pigs prior to the course. Of the 48 farmers who had pigs before the course, 38 changed at least some of their practices, with a similar rate of change across learning approaches. Approximately $75 \%$ of farmers reared cattle prior to the course. The lowest incidence was in the MM group, which also had the highest increase (9), bringing its numbers up to the average (almost all farmers) after the course. The rate of change among farmers who owned cattle before the course was highest in the FF group. Most new practices adopted across the three groups related to feeding, watering, and washing the cattle.

The number of participants with fish ponds almost doubled, from 18 before to 33 after the course, with only marginal differences between the groups. The FF group had slightly more participants with fish ponds before the course, eight compared with five in the other two groups, and a few more participants with fish ponds after the course. Almost $90 \%$ adopted at least one new technique and only two farmers in the FF group did not change, resulting in five farmers in each group changing some way in which they raised fish, adopting between one and three new practices each. There were only slight differences between the number of new techniques adopted in the three learning modes.

\section{Summary and Discussion}

Summarising farmers' reported adoption of new farming practices taught in a pilot nonformal farmer ODL project in Cambodia, this paper suggests that ODL was as effective as face-to-face lectures.

Advances in ICTs, including software platforms for ODL and instructional ODL designs, have opened new learning strategies for farmers to expand their knowledge about agricultural techniques for improved practices. The research reported in this paper focussed on the learning outcome relationships between participation in three different learning approaches. We explored whether the course type influenced the competency and capacity to assimilate and apply new knowledge and change behaviour, using selfreporting. The almost equal high rate of reported adoption across the learning modes could be interpreted as an indication that the learners had mastered the course content to a similar extent across the three learning types. There could have been some bias in the form of participants reporting exaggerated adoption rates. But as there is nothing to 
suggest such potential exaggeration would be higher in any of the groups, we did not take this potential bias into account when reaching this tentative conclusion.

The evaluation thus pointed to the relevance of ODL for farmer training by indicating that it could be as effective as face-to-face training for farmer adoption of new practices and starting new activities. However, before this result can be generalised as a conclusion, it might be necessary to conduct a similar project elsewhere in Cambodia, preferably with a larger number of participants.

The discussion in the rest of this section assumes that ODL can be an efficient mode of learning for rural farmers. There will be future opportunities to test this assumption as several organisations have started using the course material, available under a Creative Commons license for a small fee covering the cost of CD burning and distribution. It will also be available free of charge on PANdora's Web site, but this option will only be suitable for those with broadband access.

More widespread use of the course material developed for this project will reduce the average cost per user. The potential for comparatively lower costs per user of ODL than traditional face-to-face learning could not be demonstrated in this study because of the high costs of training in the production of self-learning material. Now that several staff members have been trained, these costs can be distributed across several courses. As they gain experience in designing open learning course material, it is expected that their productivity will increase as they begin to expand ODL into other subjects.

In addition to knowledge acquisition and the adoption of new practices, there could be wider development benefits and implications from an ODL course of this nature (e.g., the increased interaction between villagers as they exchange information and knowledge gained during the course). Although social interaction and inclusion were not incorporated as evaluation criteria, the literature has referred to them as possible outcomes under appropriate learning conditions, where the learning forum is also a social environment in which learners can expand their relationships and social capital (de Greef, Verte, \& Seegers, 2012).

The results are promising in that they show ODL could facilitate the engagement of farmers in more independent learning, focussing on aspects of farming that are most useful for them. While ICTs are powerful tools for aiding the transference of information, the most important aspect of the course was the content. Now that the content has been prepared and made available to other farmers across Cambodia, it should be updated on a regular basis to incorporate the latest agriculture research results. However, as many farmers lack sufficient digital literacy and equipment for this type of training, it would be necessary to establish appropriate infrastructure, including some form of intermediation, to enable them to benefit from ODL. Such infrastructure for non-formal education would be particularly important for women to enable them to engage in self-paced learning at times that fit with their other duties. Public access centres, designed to be conducive for learning, appear to be a suitable option. 
In order for non-formal ODL in agriculture to improve food security and livelihoods, it would have to scale to a national level. This would necessitate an efficient institutional framework, covering all aspects of ODL, including course development and delivery as well as appropriate venues. A critical mass of learners would be required to justify the high up-front cost of preparing the course material and providing learner support. These functions require considerable budget allocations, which must be at a level ensuring that ODL becomes affordable for low-income households. Rather than approaching ODL and traditional modes of learning as a dichotomy between two polarities, it may be more beneficial to consider the two learning approaches as complementary, where some subjects may better lend themselves to the former and others to the latter.

By focussing on adoption (albeit self-reported) in the evaluation, it became clear that the knowledge gained from absorbing the learning material was only one benefit ODL could bring to these areas. Other benefits included the adoption of new practices, the introduction of the lifelong learning concept, and the development of a community of learners. Exploring how ODL can achieve broader development objectives, including social inclusion, would be a fruitful avenue for further research as ODL is likely to become more commonly used for training in farming methods. In order to fully assess the effectiveness of ODL in informing farmers about new methods and encouraging them to adopt these, additional studies should be conducted in other parts of Cambodia. Future research could also explore whether and how a course of this nature could promote learning in households and the wider community. Also, one could research the extent to which the propensity to adopt new practices was associated with resources available to individual farmers.

\section{Acknowledgements}

We acknowledge that the research reported in this paper was supervised by Mr Pin Tara, Vice Dean of the Chea Sim University of Kamchaymear, following the research approach and guidelines prepared by one of the authors. The authors also thank the anonymous IRRODL reviewers for their constructive comments and suggestions. 


\section{References}

Aker, J . C., Ksoll, C. \& Lybbert, T. J . (2011). ABC, 123: Can mobile phones improve learning? Evidence from a field experiment in Niger. Medford, Mass.: Tufts University; Oxford, UK: University of Oxford; Davis, Calif.: University of California, Davis.

Ally, M. (Ed.) (2009). Mobile learning: Transforming the delivery of education and training. Athabasca: Athabasca University Press.

Berkvens, J ., Kalyanpur, M., Kuiper, W., \&Van den Akker, J . (2012). Improving adult learning and professional development in a post-conflict area: The case of Cambodia. International J ournal of Educational Development, 32(2), 241- 251.

Clough, G., J ones, A., McAndrew, P., \& Scanlon, E. (2009). Informal learning in online communities of mobile devices enthusiasts. In M. Ally (Ed.), Mobile learning: Transforming the delivery of education and training (pp. 99- 112). Athabasca: Athabasca University Press.

COL - Commonwealth of Learning. (2012). Lifelong learning for farmers (A compendium with articles from various sources). Retrieved from http:// www.col.org/SiteCollectionDocuments/L3Farmers_COLinAction_July2 012.pdf

De Greef, N., Verte, D., \& Segers, M. (2012). Evaluation of the outcome of lifelong learning programmes for social inclusion: A phenomenographic research. International J ournal of Lifelong Education, 31(4), 453-476.

Donkor, F. (2011). Assessment of learner acceptance and satisfaction with video-based instructional materials for teaching practical skills at a distance. The International Review of Research in Open and Distance Learning, 12(5), 7492.

Guba, E. G., \& Lincoln, Y. S. (1981). Effective evaluation. San Francisco: J ossey-Bass.

Gulati, S. (2008). Technology-enhanced learning in developing nations: A review. The International Review of Research in Open and Distance Learning, 9(1).

Hampton, C. (2002). Teaching practical skills. In A. K. Mishra \&J . Bartram (Eds.), Perspectives on distance education: Skills development through distance education (pp. 83- 91). Vancouver, Canada: Commonwealth of Learning. Retrieved from http://www.col.org/SiteCollectionDocuments/Skills_Chapter09.pdf 
Hudson, H. E. (2006). From rural village to global village: Telecommunications for development in the information age. NewJ ersey: Lawrence Erlbaum Associates.

Iqbal, S. \&Qureshi, I. A. (2012). M-learning adoption: A perspective from a developing country. The International Review of Research in Open and Distance Learning, 13(3), 147-164.

Isaacs, S., \& Hollow, D. (Eds.) (2012). The eLearning Africa 2012 report. Germany: ICWE.

J ung, I. S., Wong, T. M., Chen L., Baigaltugs, S., \&Belawati, T. (2011). Quality assurance in Asian distance education: Diverse approaches and common culture. International Review of Research in Open and Distance Learning, 12(6), 6383.

Latchem, C. (2012). Quality assurance toolkit for open and distance non-formal education. Vancouver: The Commonwealth of Learning.

Latchem, C., \& Walker, D. (Eds.) (2001). Perspectives on distance education: Telecenters: case studies and key issues. Vancouver: The Commonwealth of Learning.

Librero, F. (2010). Training Asian instructional designers. In J . Baggaley \& T. Belawati (Eds.), Distance education technologies in Asia (pp. 214-226). New Delhi: Sage.

Lockee, B., Moore, M., \& Burton, J . (2002). Measuring success: Evaluation strategies for distance education. Educase Quarterly, 1, 20-26.

Mahmood, K. (2005). Multipurpose community telecenters for rural development in Pakistan. The Electronic Library, 23(2), 204-220.

Mikalsen, A. B., Klefstad, B., Horgen, S.A., \& Hjeltnes, T. (2008). An integrated multimedia e-learning model for vocational training. Proceedings of the 6th International Conference on Networked Learning.

National Committee for Sub-National Democratic Development (NCDD). (2009). District code 1402 for Kamchay Mear databook. Phnom Penh, Cambodia: Author.

Perraton, H. (2004). Aims and purpose. In H. Perraton \& H. Lentell (Eds.), Policy for open and distance learning (pp . 9-41). New York: Routledge.

Rekkedal, T., \&Dye, A. (2007). Mobile distance learning with PDAs: Development and testing of pedagogical and system solutions supporting mobile distance 
learners. The International Review of Research in Open and Distance Learning, 8(2), 1-21.

Rogers, E. M. (2003). Diffusion of innovations (5 ${ }^{\text {th }}$ ed.). New York: Free Press. First published in 1962.

Sanderson, E., \& Kindon, S. (2004). Progress in participatory development: Opening up the possibility of knowledge through progressive participation. Progress in Development Studies, 4(2), 114- 126.

Sen, A. K. (2001). Development as freedom. London: Oxford University Press. First published in 1999.

Sulaiman, R. V., Hall, A., Kalaivani , N. J., Dorai, K., \& Reddy, T. S. V. (2012). Necessary, but not sufficient: Critiquing the role of information and communication technology in putting knowledge into use. The J ournal of Agricultural Education and Extension, 18(4), 331-346.

Tikly, L., \& Barrett, A. (2011). Social justice, capabilities and the quality of education in low income countries. International J ournal of Educational Development, 31(1), 3- 14.

United Nations (UN). (2003). Cambodia-UNTAC: Background. Retrieved from http:// www.un.org/Depts/dpko/dpko/co mission/ untacbackgr1.html.

World Bank. (2011). E-sourcebook: ICT in agriculture: Connecting smallholders to knowledge, networks, and institutions. Washington, DC: World Bank.

Wright, C. R., Dhanarajan, G., \& Reju, S. A. (2009). Recurring issues encountered by distance educators in developing and emerging nations. International Review of Research in Open and Distance Learning, 10(1), 1-25.

Yin, R. K. (1994). Case study research: Design and methods (2nd ed). Thousand Oaks, CA: Sage Publications.

\section{Athabasca University $\mathbf{Z}$}

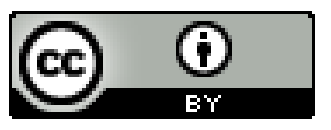

